\title{
molecules
}

ISSN 1420-3049

http://www.mdpi.org

\section{An EXAFS Study on the Local Structure Around Iron in Atmospheric Aerosols Collected in the Qingdao Area}

\author{
Jianhua Qi, Manping Zhang, Lijuan Feng and Xianguo $\mathrm{Li}^{*}$ \\ College of Chemistry and Chemical Engineering, Ocean University of China, Qingdao 266003, P. R. \\ China
}

\section{Zhi Xie and Zhihu Sun}

Hefei Synchrotron Radiation Facility, University of Science and Technology of China, Heifei 230029, P. R. China

\section{Tiandou Hu}

XAFS Station of Beijing Synchrotron Radiation Facility, Institute of High Energy Physics, Chinese Academy of Sciences, Beijing 100039, P. R. China

* Author to whom correspondence should be addressed. Tel. (+86)-532-2032482-8318, Fax (+86)-532 -2032483, E-mail: lixg@mail.ouc.edu.cn

\begin{abstract}
The existing forms of $\mathrm{Fe}$ are of great interest since they have a profound effect on the biological availability of Fe. In this work, aerosol samples collected in different seasons and at different locations in the Qingdao region were examined by means of extended X-ray absorption fine structure (EXAFS) K-edge analysis of Fe, X-ray diffraction (XRD) and Fe content analysis. The results showed that an iron ion in aerosol particles is surrounded on average by 5.8 (coordinated) $\mathrm{O}$ ions. For the six samples examined, the coordination number of the first $\mathrm{Fe}-\mathrm{O}$ coordination subshell is always 3 with a coordination distance (with $\mathrm{O}$ ) in the range of 1.952 1.966 $\pm 0.002 \AA$, while the coordination number of the second subshell varies from 2.2 to 3.0 with a coordination distance of $2.108 \pm 0.002 \AA$. The coordination is approximately consistent with that of $\alpha-\mathrm{Fe}_{2} \mathrm{O}_{3}$, suggesting that iron in aerosol samples is mainly present in the form of $\alpha-\mathrm{Fe}_{2} \mathrm{O}_{3}$. The fact that the coordination number in the second subshell is smaller than that of $\alpha-\mathrm{Fe}_{2} \mathrm{O}_{3}$ might be an indication that there is a small amount of
\end{abstract}


$\mathrm{FeO}$ mixed with $\alpha-\mathrm{Fe}_{2} \mathrm{O}_{3}$ in aerosol particles. Existence of $\mathrm{FeO}$ is confirmed by a later XRD experiment.

Keywords: Atmospheric aerosol; EXAFS; iron speciation; Qingdao.

\section{Introduction}

Atmospheric aerosols are particles and/or droplets suspended in air [1]. They play very important roles in atmospheric processes [2], environmental quality [3], and the biogeochemical cycles of trace elements and compounds [4], even though they contribute very little to the atmospheric constituents of the earth.

Trace metal elements loaded in aerosol particles are of great interest since they have profound effects on the geochemical cycle of metals and on the marine ecosystem. Recent research showed that atmospheric dry deposition is one of the major paths for the input of trace metals to waters [5-7]. The environmental effect is directly determined by the aerosol composition, concentration and chemical species of metals in aerosolparticles. Iron in seawater is especially important for the oceanic ecosystem, because the primary oceanic productivity is actually limited in many cases by iron in addition to nutrients [8,9]. The rule s of transfer and transformation and the biological availability of iron in waters depend on its form and chemical species present [10-12], not on its total concentration. Therefore, it is important to study iron speciation and transformation.

It is very difficult for conventional X-ray diffraction (XRD) method to detect the local structures of iron in aerosol particles because of its low content. Fluorescence spectrum of EXAFS was developed in recent years, and it can obtain local structure information for samples whose concentration is no less than about ten ppm. It can therefore be used to study crystaland non- crystal samples, including solid s, liquid s and even gases $[13,14]$. In this work, the characteristics and variation of the local iron structures for aerosol samples collected in different seasons (spring and summer) and at different sites in the Qingdao area were examined by means of Fe K-edge EXAFS analysis.

\section{Experimental}

\section{Sample collection}

Three sampling sites, Yangkou, Baguanshan and Cangkou, denoted as sites \#1, \#2 and \#3 respectively, are located near the coast of the Qingdao area. These sampling sites represent different functional districts and environmental settings. Yangkou (\#1) lies near the shore of the Yellow Sea, at the foot of Laoshan Mountain, and there is smaller anthropogenic influence owning to less pollution emission sources. The Baguanshan site (\#2) is located on the top of a hill, on the downtown campus of Ocean University of China, and represents a utility and residential area. The Cangkou sampling site (\#3) is surrounded by industrial estates (such as Qingdao Steelworks, Qingdao Chemical Plant, etc.). 
The corresponding TSP (total suspended particles) of samples collected at these three sites during the spring season were denominated as Spr-1, Spr-2 and Spr-3 respectively. At site \#2, we collected $\mathrm{PM}_{10}$ (particles with aerodynamic diameter less than $10 \mu \mathrm{m}$ ) samples in spring and summer, represented as Spr-2P and Sum-2P respectively. Sample collection was carried out using a KB-120 air sampler, and the ambient particles were separated on $0.4 \mu \mathrm{m}$ pore size Nuclepore filters. The sampler was mounted and secured at a high platform during the entire sampling period, and the volume of air sampled was monitored by using a flowmeter, which was calibrated by a qualified organization The sampler was operated for a 20 -h period during each sampling to collect about $100 \mathrm{~m}^{3}$ of air. Aclear plastic nipper and disposable plastic gloves should be used during the whole process to avoid external pollution. The plastic nipper and filter containers were soaked for two weeks in a $50 \% \mathrm{HCl}$ bath, and then rinsed with sub-boiling water. The filters were also pretreated with $15 \% \mathrm{HCl}$ solution for $48 \mathrm{~h}$ and rinsed at a clean bench in the laboratory. For the transport to and from the sampling sites, the sampling materials were kept inside a double plastic bag which was also pretreated with dilute $\mathrm{HCl}$ solution.

\section{EXAFS}

The EXAFS experiments were carried out in fluorescence mode on Beam 4WB1 at the Beijing Synchrotron Radiation Facility (BSRF). The storage ring was operated with an electron energy of $2.2 \mathrm{GeV}$ and a typical current of $50 \mathrm{~mA}$ was used during the experiment. A Si(111) double crystal monochromator was employed. Higher harmonics were rejected by detuning the Bragg angle of the second crystal of the monochromator. The samples were placed with an angle of 45 ?against incident $\mathrm{X}$-rays. The fluorescence signal was detected by a Lytle fluorescence ionization chamber Interference of dispersion was eliminated by using a Mn filter. The K-edge of iron element positioned at $7112 \mathrm{eV}$ was used for calibration. The filter membranes with aerosol particles were folded in half (with a detection area of $0.5 \times 1 \mathrm{~cm}$ ) and mounted on a sample holder with Scotch tape. The absorption spectra of $\alpha-\mathrm{Fe}_{2} \mathrm{O}_{3}$ and six aerosol samples were collected. Fine powder of $\alpha-\mathrm{Fe}_{2} \mathrm{O}_{3}$ was chosen as standard and measured in transmission mode. The detection limit of iron with fluorescence method is about $20 \mathrm{ppm}$.

A blank filter membrane was examined to clarify the possible interference caused by filters. The result showed that the interference is negligible.

$X R D$

The XRD patterns were obtained on a refitted Rigaku $12 \mathrm{~kW}$ rotating anode X-ray diffractometer using $\mathrm{CuK}_{\alpha}$ radiation $(\lambda=0.1541 \mathrm{~nm})$. A voltage of $40 \mathrm{kV}$ and a current of $120 \mathrm{~mA}$ were employed. The

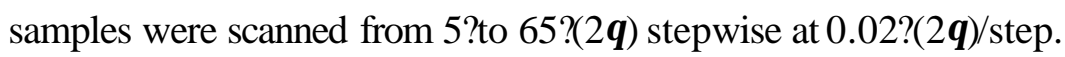

\section{Iron content measurements}

The aerosol samples loaded on filters were dried in a desiccator until the weights were constant, and were then weighed. The iron content in aerosol samples was determined by means of atomic absorption 
spectrometry (AAS). Prior to the analysis, a sample was digested with ultrapure $\mathrm{HNO}_{3}(2.0 \mathrm{~mL}), \mathrm{HClO}_{4}$ $(2.0 \mathrm{~mL})$ and $\mathrm{HF}(2.0 \mathrm{~mL})$ in a Teflon bomb for 3 to 4 hours at $160^{\circ} \mathrm{C}$. The solution was then heated until it was completely dry, followed by cooling for a period of 1 hour. Next, the residue was dissolved with $1.0 \mathrm{~mL}$ ultrapure $\mathrm{HNO}_{3}$ and transferred into a $10 \mathrm{~mL}$ colorimetric tube. The volume of the resulting solution was fixed to $10 \mathrm{~mL}$ with sub-boiling water.

Samples were subsequently analyzed with graphite-furnace atomic absorption spectrometry. The sample injection volume is $10 \mu \mathrm{L}$, with the flow rate of argon gas being $200 \mathrm{~mL} \cdot \mathrm{min}^{-1}$. The precision of this method was $3.2(\mathrm{RSD} \%)$, whereas the detection limit and the recovery efficiency of iron were $0.0087 \mu \mathrm{g} / 10 \mathrm{~mL}$ and $95.1 \%$ respectively. The results are given in Table 1 .

\section{Results and Discussion}

\section{EXAFS data analysis}

The EXAFS function $\chi(k)$ is customarily expressed as following:

$$
\chi(k)=\sum_{j}\left(\frac{N_{j}}{k R_{j}^{2}}\right) S_{i}(k) F_{j}(k) e^{-2 \sigma_{j}^{2} k^{2}} e^{-2 R_{j} / \lambda(k)} \sin \left(2 k R_{j}+\phi j(k)\right)
$$

where $k$ is the photoelectron wave number and $S_{i}(k)$ is a dimensionless functio $n$ of $k$ assigned to the attenuation of the EXAFS signal due to multiple excitation effects; $F_{j}(k), \Phi_{j}, \sigma_{j}, \lambda(k)$ are the $j$ th atoms' backscattering amplitude function, energy dependent phase shift in the photoelectron wave, Debye-Walker factor and the photoe lectron mean free path respectively; $R_{j}, N_{j}$ are the mean internuclear distance between the central atom and the atoms of the $j$ th neighbour shell and the coordination number of the $j$ th shell respectively. The aim of EXAFS data analysis is to obtain the se unknown parameters in above formula, namely $R_{j}, N_{j}$ and $s_{j}$.

The EXAFS data analysis was performed according to conventional procedure [15], and was accomplished by applying NSRLXAFS software developed by XAFS Station of Hefei Synchrotron Radiation Facility, University of Science and Technology of China.

The experimental data were first converted into absorption curve $\mu(E)$-E. Figure 1 shows the absorption curve of $\alpha-\mathrm{Fe}_{2} \mathrm{O}_{3}$ standard and aerosol samples. The New Victoreen formula (with photon energy $E$ and parameters $a, b, c)$,

$$
\mu^{\prime}=\mathrm{aE}^{-3}+\mathrm{bE}^{-4}+\mathrm{c}
$$

was used to remove the pre-edge background. The post-edge background was fitted by three section cubic spline function. After the removal of the post-edge background, the atomic absorption coefficient $\mu_{0}$ is then obtained. 

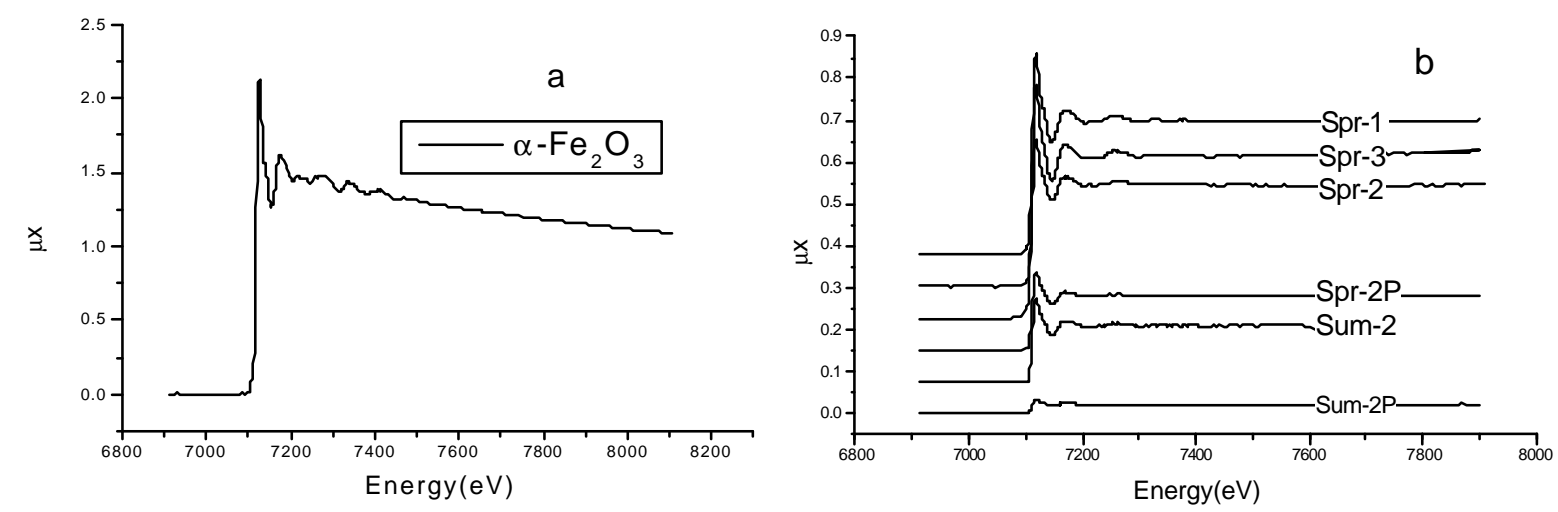

Figure $1 \mathrm{Fe} \mathrm{K}$-edge absorption spectra of $\alpha-\mathrm{Fe}_{2} \mathrm{O}_{3}(\mathbf{a})$ and aerosol samples (b).

To eliminate the effect caused by samples with different thickness, the data must be normalized first. The normalization factor is the height of the absorption edge, which is generally determined by the height difference between the pre-edge and post-edge curves. The function $\chi(\mathrm{E})$ can then be derived by using the following formula

$$
\chi=\frac{\mu-\mu_{0}}{\Delta \mu_{0}}
$$

where $\Delta \mu_{0}$ is the altitude of transmission jump at absorption edge $\mu_{0}$.

The EXAFS basic formula, $\chi(k)$ (Equation 1) is a function of photoelectron wave number $(k)$, instead of a function of energy (E). Therefore, it is necessary to convert the derived EXAFS (Equation 3) from energy space into wave number space as a function of $k$, which is given by

$$
k=\frac{\sqrt{2 m\left(E-E_{0}\right)}}{\hbar}
$$

where $\mathrm{m}$ is the electron mass and $E_{0}$ is the threshold excitation energy of the photoelectron; $\hbar$ is the normalized Planck constant. The EXAFS spectra $\chi(k) \sim k$ were then obtained, and a weight factor of $k^{2}$ was applied to compensate the swing attenuation effect.
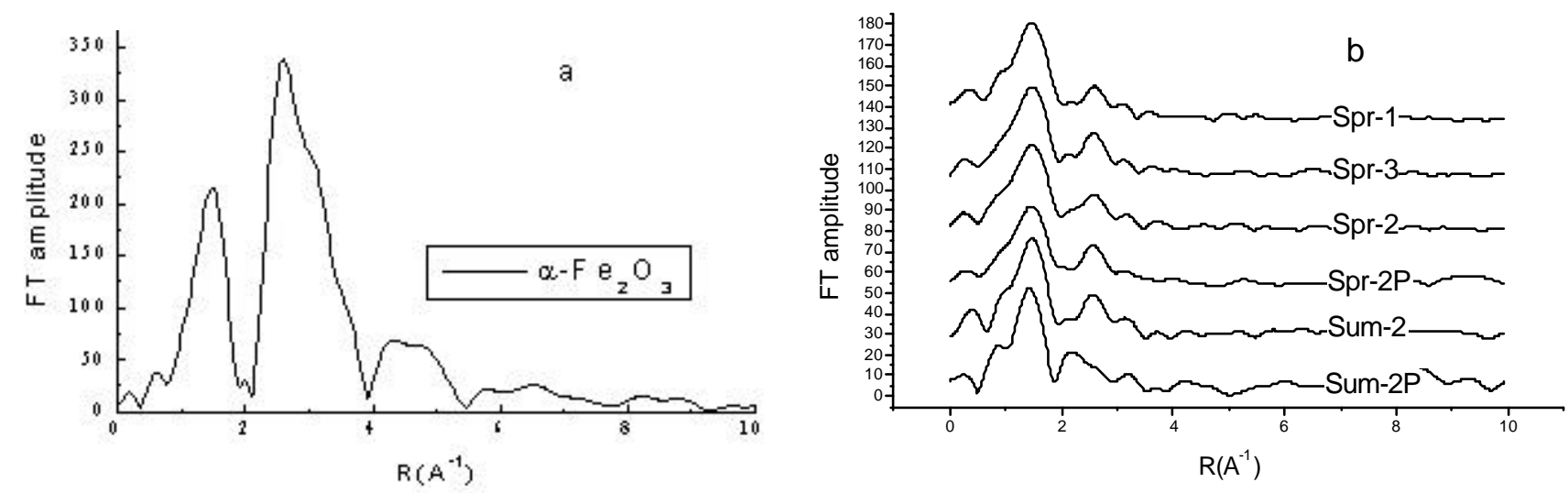

Figure 2 The $\mathrm{RDF}$ of $\alpha-\mathrm{Fe}_{2} \mathrm{O}_{3}(\mathbf{a})$ and the samples (b). 
To extract the structural signals from the background, the next step in the analysis is to Fourier transform (FT) the $k^{2}$-weighted EXAFS signal $\left(k^{2} \chi(k)\right)$ using the region from 3.0 11.0 $\AA^{-1}$. This converts the data from a representation in terms of $k$ to that in terms of coordinate space $R$ and gives an overview of the average radial distribution (RDF) in material. Typical results of $F T\left(k^{2} \chi\right)$ for the $\alpha-\mathrm{Fe}_{2} \mathrm{O}_{3}$ standard and aerosol samples are presented as solid lines in Figure 2. The first peak on the RDF at 1.9 (Figure 2) corresponds to the contribution of $\mathrm{O}$ ligands in the first coordination sphere of Fe atom (RDF distance was not corrected for phase shift). The contribution at higher distance (2.9 3.5 $)$ corresponds to the $\mathrm{Fe}-\mathrm{Fe}$ bond in the second sphere. To obtain the EXAFS signal of the first coordination sphere of the absorption atom (solid lines in Figure3), the first RDF peak was selected using a window function, then filtered and back Fourier transformed into $k$ space.

In order to calculate the local structure parameters around the absorption atom using EXAFS basic formula (Equation 1), two key parameters, i.e. phase shift $\Phi_{\mathrm{j}}(k)$ and backscattering amplitude $\mathrm{F}_{\mathrm{j}}(k)$, must be known in advance. These two parameters in this work were generated by FEFF6 software package [16].

We first fitted the data using single oxygen atomic shell, but no reasonable results were obtained. It occurred to us that the Fe-O coordination of the samples couldn't be explained with one single Fe-O coordination shell.

The space group of $\alpha-\mathrm{Fe}_{2} \mathrm{O}_{3}$ is $\mathrm{R} 3 \mathrm{c}$. Fe is octahedrally coordinated with 6 (coordinated) $\mathrm{O}$ ions. There are 3 long Fe-O bonds and 3 short ones, with bond length be ing $2.115 \AA$ and $1.945 \AA$ A respectively. Considering the coordination state of $\mathrm{Fe}$ ion in $\alpha-\mathrm{Fe}_{2} \mathrm{O}_{3}$, we assume that $\mathrm{O}$ ions around $\mathrm{Fe}$ ion in aerosol samples also lie in two coordination shell of different distances. The fitting was then performed using two oxygen atomic shells with the nonlinear least square method, and a very much better result was obtained. Figure 3 shows the fitting plot of the calculated spectra (open circle) and the experimental spectra (solid line) for $\alpha-\mathrm{Fe}_{2} \mathrm{O}_{3}$ and aerosol samples.
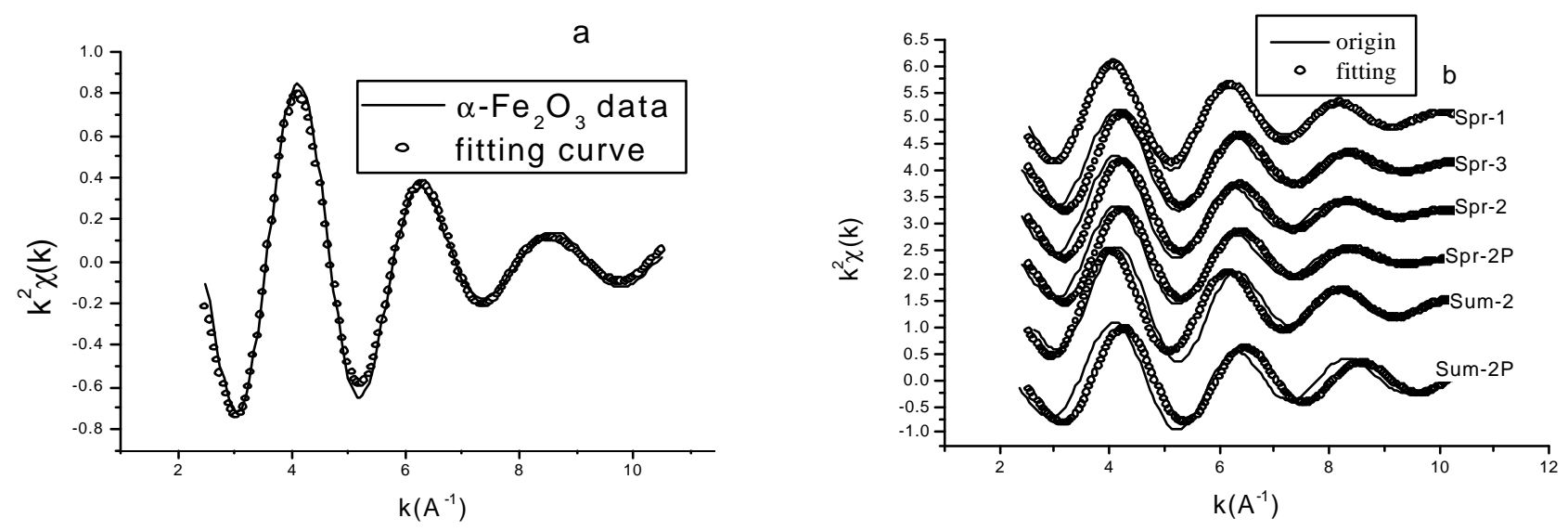

Figure 3. $k^{2}$-Weighted EXAFS and the fitting curve for iron $\mathrm{K}$-edge of $\mathrm{Fe}-\mathrm{O}$ coordination shell of $\alpha-\mathrm{Fe}_{2} \mathrm{O}_{3}$ (a) and aerosol samples (b). 


\section{EXAFS analysis results}

As shown in Figure 3, the fitting results are good. The large noise of the EXAFS signals, which are caused by the low content of total iron in our aerosol samples, might be responsible for the fitting errors. Table 1 gives the results of all samples collected in spring and summer along with an $\alpha$ - $\mathrm{Fe}_{2} \mathrm{O}_{3}$ standard. The results indicated that each Fe ion in the nearest coordination shell is surrounded on average by 5.8 (coordinated) $\mathrm{O}$, forming an aberrant octahedron. Three of the oxygen atoms are located at a distance of $1.959 \pm 0.002 \AA$ and 2.8 at $2.108 \pm 0.002 \AA$. For the six samples examined, the coordination number of the first Fe-O coordination subshell is always 3 with a coordination distance (with $\mathrm{O}$ ) in the range of $1.952 \sim 1.966 \pm 0.002 \AA$, while the coordination number of the second subshell varies from 2.2 to 3.0 with a coordination distance of $2.108 \pm 0.002 \AA$. The coordination state is approximately consistent with that of $\alpha-\mathrm{Fe}_{2} \mathrm{O}_{3}$, and this suggests that iron in aerosol samples mainly presents in the form of $\alpha-\mathrm{Fe}_{2} \mathrm{O}_{3}$. We also found that in aerosol samples the number of $\mathrm{O}$ neighbors around $\mathrm{Fe}$ in the second subshell is lower than that for $\alpha-\mathrm{Fe}_{2} \mathrm{O}_{3}$, which might be an indication that there is a small amount of $\mathrm{FeO}$ mixed with $\alpha-\mathrm{Fe}_{2} \mathrm{O}_{3}$ in aerosol particles. The similar result was also found in iron-loaded coal chars [17].

Table 1 Iron contents and coordination parameters of Fe-O coordination shell for $\alpha-\mathrm{Fe}_{2} \mathrm{O}_{3}$ and aerosol samples.

\begin{tabular}{|l|l|l|l|l|l|}
\hline Sample & $\begin{array}{c}\text { Fe content } \\
(\%)\end{array}$ & $\begin{array}{c}\text { First subshell of } \\
\text { Fe-O coordination } \\
\mathrm{R}_{1}(\AA)\end{array}$ & $\begin{array}{c}\text { Coordination } \\
\text { number of the first } \\
\text { subshell, } \mathrm{N}_{1}\end{array}$ & $\begin{array}{c}\text { Second subshell of } \\
\text { Fe-O coordination } \\
\mathrm{R}_{2}(\AA)\end{array}$ & \multicolumn{1}{|c|}{$\begin{array}{c}\text { Coordination } \\
\text { number of the } \\
\text { second subshell, } \mathrm{N}_{2}\end{array}$} \\
\hline$\alpha-\mathrm{Fe}_{2} \mathrm{O}_{3}$ & & 1.945 & 3 & 2.115 & 3 \\
\hline $\mathrm{Spr}-1$ & 1.77 & $1.966 \pm 0.002$ & $3.05 \pm 0.05$ & $2.108 \pm 0.02$ & $3.01 \pm 0.05$ \\
\hline $\mathrm{Spr}-2$ & 3.18 & $1.956 \pm 0.002$ & $3.05 \pm 0.05$ & $2.108 \pm 0.02$ & $3.01 \pm 0.05$ \\
$\mathrm{Spr}-2 \mathrm{P}$ & 2.76 & $1.952 \pm 0.002$ & $3.05 \pm 0.05$ & $2.108 \pm 0.02$ & $2.91 \pm 0.05$ \\
\hline Spr-3 & 3.10 & $1.960 \pm 0.002$ & $3.02 \pm 0.05$ & $2.108 \pm 0.02$ & $2.91 \pm 0.05$ \\
\hline Sum-2 & 0.82 & $1.963 \pm 0.002$ & $3.05 \pm 0.05$ & $2.108 \pm 0.02$ & $2.67 \pm 0.05$ \\
\hline Sum-2P & 0.68 & $1.958 \pm 0.002$ & $3.05 \pm 0.05$ & $2.108 \pm 0.02$ & $2.19 \pm 0.05$ \\
\hline
\end{tabular}

An XRD experiment for aerosol samples was carried out later. The diffraction pattern of one of the samples was displayed in Figure 4. We can find that the Nuclepore filter loaded with aerosol particles owns a strong diffraction signal and interferes with the signals of $\mathrm{FeO}$ and $\alpha-\mathrm{Fe}_{2} \mathrm{O}_{3}$. This results in the poor diffraction pattern. Computerized qualitative analysis according to JCPDS powder diffraction files showed that there are $\alpha-\mathrm{Fe}_{2} \mathrm{O}_{3}, \mathrm{FeO}$ and $\mathrm{Al}(\mathrm{OH})_{3}$ in the sample. It illuminates that iron lies in aerosol particle not only in the form of $\alpha-\mathrm{Fe}_{2} \mathrm{O}_{3}$ but also in the form of $\mathrm{FeO}$ in a measure. 


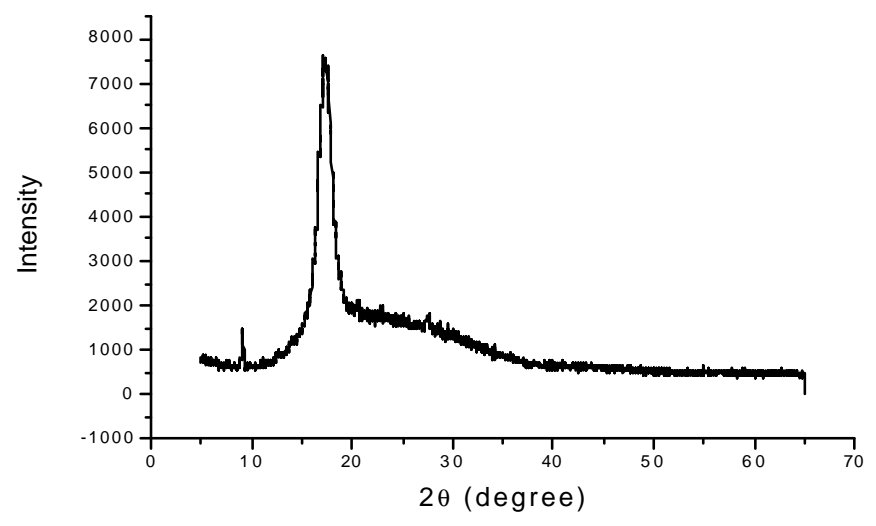

Figure 4. The XRD spectra of an aerosol sample.

For the TSP and $\mathrm{PM}_{10}$ samples collected at sampling site \#2 during spring and summer, the coordination of the first $\mathrm{Fe}-\mathrm{O}$ subshell is similar, but the coordination number of the second subshell for $\mathrm{PM}_{10}$ is lower than that for TSP. This is probably caused by the higher content ratio of $\mathrm{FeO}: \alpha-\mathrm{Fe}_{2} \mathrm{O}_{3}$ in fine particles than in coarse particles. This inference needs to be further confirmed by means of other speciation methods.

\section{Summary and Conclusions}

In this paper, we obtained the near-neighbour coordination parameters of $\mathrm{Fe}$ ions by analysis of $\mathrm{Fe}$ $\mathrm{K}$-edge fluorescence EXAFS spectra for aerosol samples collected in the near shore region of Qingdao. In aerosol particles, iron is mainly present in the form of $\alpha-\mathrm{Fe}_{2} \mathrm{O}_{3}$, with a small amount of mixed $\mathrm{FeO}$. Iron concentration in aerosols collected in Qingdao region, especially for those collected in summer, is very low. This leads to the large noise in the EXAFS signals and causes difficulties for structural parameter determination and gives limited information. The EXAFS technique would provide more useful structural information for iron(III) and iron(II) in aerosol particles if high-dust samples with higher iron content were collected.

\section{Acknowledgements}

This project was supported by NSFC under the Grant No. 49976020, and partly by BSRF, Institute of High Energy Physics, Chinese Academy of Sciences. The authors would like to express their thanks to the XAFS Station of Beijing Synchrotron Radiation Facility, the Hefei Synchrotron Radiation Facility of University of Science and Technology of China, and the MicroStructure Analytical Laboratory of Peking University. The authors gratefully acknowledge very helpful discussions with Prof. Shiqiang Wei. 


\section{References}

1. Wang, M.X. Atmospheric Chemistry. China Meteorological Press: Beijing, 1999; pp166-244.

2. Iwasaka, Y.; Yamato, M.; Imasu, R.; Ono. A. Transport of Asian dust (KOSA) particles - importance of weak KOSA events on the geochemical cycle of soil particles. Tellus 1988, 40B, 494-503.

3. Jiang, Y.R.; Gao, Q.X. Review of atmospheric aerosol impact on climate and ecosystem. Chinese Res. Environ. Sci. 1998, 11, 17-21.

4. Lin, F.J.; Hsu, S.C.; Jeng, W.L. Lead in the southern East China Sea. Mar. Environ. Res. 2000, 49, 329-342.

5. Tindale, N.W.; Pease, P.P. Aerosols over the Arabian Sea: atmospheric transport pathways and concentrations of dust and seasalt. Deep-Sea Res. Part II: Topic Studies in Oceanography. 1999, 46, $1577-1595$.

6. Spokes, L.; Jickells, T.; Jarvis, K. Atmospheric inputs of trace metals to the northeast Atlantic Ocean: the importance of southeasterly flow. Mar. Chem. 2001, 76, 319-330.

7. Herut, B.; Nimmo, M.; Medway, A.; Chester, R.; Krom, M.D. Dry atmospheric inputs of trace metals at the Mediterranean coast of Israel (SE Mediterranean): sources and fluxes. Atmos. Environ. 2001, 35, 803-813.

8. Duce, R. A. The impact of atmosphere nitrogen, phosphorus, and iron species on marine biological productivity, in The Role of Air-Sea Exchange in Geochemical Cycling, Buat-Menard P., Ed.; Reidel, D.: Dordrecht, 1986; pp 497-529.

9. Wells, M.L.; Price, N.M.; Bruland, K.W. Iron chemistry in seawater and its relationship to phytoplankton: a workshop report. Mar. Chem. 1995, 48, 157-182.

10. Zhuang, G.S.; Yi, Z.; Duce, R.A.; Brown, P.R. Chemistry of iron in marine aerosols. Glob. Biogeochem. Cycles. 1992, 6, 161-173.

11. Zhuang, G.S.; Yi, Z.; Duce, R.A.; Brown, P.R. Link between iron and sulfur suggested by the detection of $\mathrm{Fe}$ (II) in remote marine aerosols. Nature 1992, 355, 537-539.

12. Gledhill, M.; ven den Berg, C.M.G.; Nolting, R.F.; Timmermans, K.R. Variability in the speciation of iron in the northern North Sea. Mar. Chem. 1998, 59, 283-300.

13. Wang, Q.W.; Liu, W.H. X-ray absorption fine structure and its application. China Science Press: Beijing, 1994; pp 52-100.

14. Ma, L.D.; Yang F.J. Introduction to Synchrotron Radiation Applications. Fudan University Press: Shanghai, 2001; pp 149-191.

15. Sayers, D.E.; Bunker, B.A. X-ray absorption, principles, applications, techniques of EXAFS, SEXAFS and XANES; Konmingsberger, D.C.; Prins, R., Eds.; John Wiley: New York, 1988; pp 211-253.

16. Rehr, J.J.; Mustre de Leon J.; Zabinsky, S.I. Theoretical X-ray absorption fine structure standards. J. Am. Chem. Soc. 1991, 113, 5135-5140.

17. Zhu, Z.P.; Cui, H.; Li, Y.M. Study of iron chemical forms in iron-loaded coal chars. Chinese J. Fuel Chem. Technol. 1996, 24,125-130.

C 2003 by MDPI (http://www.mdpi.org). Reproduction is permitted for noncommercial purposes. 